\title{
Despojo territorial y campañas de exterminio indígena en el noreste santafecino (1866-1890)
}

Aldo Gastón Green*

Fecha de recepción: 22 de junio de 2020. Fecha de aceptación: 2 de octubre de 2020
Palabras clave

indígenas relaciones interétnicas colonización frontera chaqueña

\section{Resumen}

A fines del siglo XIX, se produjo la expansión territorial del Estado argentino en la región chaqueña. En el noreste de la actual provincia de Santa Fe esta fue precedida por la colonización efectuada por inmigrantes europeos y norteamericanos que emprendieron expediciones armadas contra los indígenas mocovíes de la zona. Aunque estas campañas se realizaron especialmente en la década de 1870 se prolongaron al menos hasta 1890. En este artículo se analizan y discuten en profundidad las características y la finalidad de las mismas. En base al examen de informes elevados por colonos, debidamente confrontados y complementados con otra documentación de la época, se sostiene que dichas expediciones no solo buscaban desplazar a los indígenas de sus tierras sino exterminarlos. El trabajo presenta además un aporte para el estudio de la sociedad, la economía y la cultura de los mocovíes de la segunda mitad del siglo XIX.

\section{Territorial dispossession and indigenous extermination campaigns in the Northeast of Santa Fe Province (1866-1890)}

\begin{abstract}
At the end of the 19th century, the Argentine State campaigned across the Chaco region to extend its territory. Earlier, European and American immigrants had colonized the northeast area of present-day Santa Fe Province and raided against Mocoví people, already settled there. Although these campaigns took place particularly throughout the decade of 1870 they continued at least until 1890. This article analyzes and discusses their characteristics and purposes in detail. After examining the reports of the colonists involved in many of the incursions and comparing them with complementary documents of the time, it is claimed that these campaigns sought displacement and annihilation of the indigenous people. Moreover, this work contributes to the study of Mocoví society, economy, and culture during the second half of the 19th century.
\end{abstract}

Key words

Indigenous people interethnic relationships colonization Chaco border

\footnotetext{
*Universidad Nacional del Litoral. Facultad de Humanidades y Ciencias. Ciudad de Santa Fe, Santa Fe. Email:
} aldogaston_32@hotmail.com 


\section{Introducción}

Durante el último tercio del siglo XIX, y en el marco de una creciente vinculación con el mercado mundial, se produjo la expansión territorial del Estado argentino en la región chaqueña. La misma tuvo como uno de sus ejes la realización de campañas militares contra los indígenas, las que se extendieron hasta la década de 1930 (Spota, 2010). Las políticas estatales que efectivizaron este proceso expansivo, tanto en el Chaco como en la Patagonia, han dado lugar a su discusión en términos de genocidio indígena -en trabajos como los del dossier publicado recientemente en Memoria Americana. Cuadernos de Etnohistoria 27-2 (Lenton y Nagy, 2019), entre otros (Roulet y Garrido, 2011; Tamagno, 2011; Lenton et al., 2015).

En el actual territorio noreste de la provincia de Santa Fe el avance estatal fue precedido por la colonización efectuada por inmigrantes europeos y estadounidenses, quienes emprendieron ataques armados contra la población indígena, especialmente en la década de 1870 prolongándose al menos hasta 1890, con el consentimiento y, en algunos casos, el apoyo logístico tanto del Estado nacional como provincial.

Estas acciones desarrolladas por los colonos han sido consideradas por otros autores, en general, como una reacción ante los ataques indígenas (Duarte, 1970; Maffucci Moore, 2007; Dosztal, 2013, 2016). En este trabajo nos proponemos principalmente analizar y discutir en profundidad las características y la finalidad de las mismas, pero también sus efectos sobre la población nativa como un aporte al estudio de las relaciones interétnicas en ese espacio de frontera.

El problema de las fronteras ha generado desde hace décadas numerosos estudios que, en el caso de Argentina -por lo dicho respecto del Chaco y la Patagonia- revisten una especial importancia. En términos generales se pone énfasis en el dinamismo de estos espacios, entendidos no solo como divisorios sino como lugares de interacción compleja entre sociedades diversas, con un abanico de posibilidades entre la negociación y el conflicto, la oposición y el mestizaje (Battcock et al., 2004; Nacuzzi, 2010; Spota, 2010; Dosztal, 2016). A su vez, se reconoce la diversidad de los mismos tanto en el amplio escenario de Latinoamérica como en el caso de Argentina (Martirén, 2014), incluso en zonas próximas entre sí (Lucaioli, 2010; Nacuzzi, 2010).

A partir de un concepto amplio de frontera, entendida como "aquel espacio en el que coexistían y/o contendían dos o más culturas diferentes, y donde la injerencia efectiva del aparato estatal resultaba disímil" (Martirén, 2014: 84), Martirén ha analizado, la convivencia de inmigrantes europeos y criollos con sus formas de organización social y económica contrastantes, entre 1856 y 1875. Por nuestra parte, en un trabajo anterior centrado en las relaciones interétnicas, hemos destacado el conflicto entre indígenas e inmigrantes en el mismo espacio y período (Green, 2018).

La zona que aquí nos interesa, el noreste santafesino, ha sido abordada por Dosztal (2016) a partir del concepto de frontera de colonización, indicando la interacción dialéctica que se produce entre límite y frente expansivo en los procesos colonizadores. La autora concibe así a la frontera como "un espacio social de violencia institucionalmente avalada que se conforma históricamente, en donde se articulaban relaciones económicas y políticas entre sociedades plurilingües y pluriculturales" (Dosztal, 2016: 122). Caracteriza a la política 
de ocupación de ese espacio -entre 1866 y 1904- como un "bloque expansivo colonizador" (Dosztal, 2016: 122) y se concentra en la experiencia y el rol de los colonos quienes, precediendo al avance militar, se instalaron más allá de los fortines.

$\mathrm{Al}$ entender que un frente de expansión lo es de retracción al mismo tiempo, y que el avance no se realizó -en este caso- sobre un territorio virgen, consideramos que su ocupación se verificó como invasión, implicando el despojo de quienes estaban allí, los indígenas mocovíes. En primer lugar procuraremos ocuparnos de ellos, ya que suelen aparecer de manera difusa en los trabajos dedicados al tema. Aunque en los últimos años se han realizado excelentes estudios sobre los mocovíes de los siglos XVIII (Nesis, 2005) y XIX (Citro, 2006; Rosan, 2016), creemos necesario examinar su arraigo social y cultural en ese espacio concreto, que transitaban, explotaban y normativizaban durante la segunda mitad del siglo XIX. En segundo lugar, intentaremos abordar el proceso colonizador y su significado, observando ambos lados de la frontera para detenernos finalmente en el análisis de las expediciones mencionadas. Para ello contamos especialmente con los informes elevados al gobierno provincial por los propios colonos -uno de ellos un prolijo diario redactado por Grobet en ocasión de tres de esas campañas realizadas en 1875-, que analizaremos, además de confrontarlos y complementarlos con otra documentación de la época. Basándonos en los propios dichos de los colonos, y en sus prácticas concretas, sostenemos que sus expediciones no solo tenían como propósito despojar a los indígenas de sus tierras sino también exterminarlos como grupo diferente, sin hacer distinción entre sus miembros.

\section{Los dueños del desierto}

El sector noreste del actual territorio provincial santafesino -Departamentos de San Javier, General Obligado y Vera-, amplio espacio que desde la población de San Javier como vértice sur se extiende entre los ríos Paraná, por el Este, y Calchaquí-arroyo Golondrina, por el Oeste, hasta el límite con Chaco, se hallaba, a mediados del siglo XIX, fuera del territorio bajo control efectivo de los estados nacional y provincial. Desde la sociedad estatal, sin embargo, se lo consideraba como propio y se lo presentaba como desierto.

Esta noción más que invisibilizar a sus habitantes indígenas, lo que resultaba imposible ante la materialidad de una frontera erigida de fuertes, cantones, tropas y cañones que separaban a dos sociedades frecuentemente enfrentadas, les negaba el derecho a poseer ese territorio en el que habían mantenido su independencia, tanto del dominio español como republicano (Bartolomé, 2003).

En dicha época, el espacio delimitado pertenecía efectivamente a los mocovíes (moqoile'ec) y espineros (ischipile'ec), que eran una parcialidad de los primeros, y limitaban al norte con los tagñilek o tobas del sur (Green, 2005). Por su parte, la sociedad criolla clasificaba a los indígenas del Chaco austral principalmente como montaraces y reducidos. La primera categoría se aplicaba a todos los que permanecían independientes al norte de la frontera, y no coincidía con la de montaraces -o noenagace'ec- que empleaban los propios mocovíes para designar a otra de sus parcialidades (Green, 2005). Sobre la costa del Paraná y al sur de los fortines se encontraban las reducciones de Calchines, Cayastá y San Javier, principalmente de mocovíes que se mantenían relativamente en paz. En 1873 fue creada la reducción de Concepción de Reconquista, al norte del territorio señalado. Muchos indígenas reducidos fluctuaban, sin embargo, 
entre las poblaciones y los montes, y grupos de javierinos se desplazaban por ese espacio nororiental de la frontera junto a los llamados montaraces por los criollos.

Los informes producidos por los ejecutores de las expediciones privadas realizadas contra los grupos indígenas de la zona durante la década de 1870 nos proporcionan datos referidos a su cultura material, formas de subsistencia, organización sociopolítica y creencias los que, contrastados y complementados con otros documentos de la época nos permiten realizar algunos aportes al conocimiento etnográfico de los mocovíes de la segunda mitad del siglo XIX. Al mismo tiempo, nos trasladan la imagen de un territorio habitado, explotado y vivido que contrasta fuertemente con la del desierto construida en la época por la sociedad estatal.

Junto a la pintura del paisaje, especialmente en el diario de la expedición de septiembre de $1875,{ }^{1}$ que con su rica fauna y flora parece haber ejercido alguna fascinación sobre los expedicionarios, se observa la omnipresencia indígena que lo modela. No se trataba de tierras vírgenes y se las reconocía explícitamente como "territorio indio", fuera de "la frontera exterior" ${ }^{2}$ que avanzaba hacia el norte.

Los colonos encuentran tolderías habitadas a las que asaltan, y otras abandonadas, diferencian en sus relatos las tolderías chicas de las grandes y, a veces, indican el número aproximado de sus habitantes o la cantidad de viviendas que las componen. A su vez, aluden a los tamaños, formas y solidez de estas, como a los materiales empleados en sus construcciones.

Es posible identificar, de esta forma, tolderías grandes de alrededor de 100 habitantes o más, asociadas a un número de ranchos en torno a los veinte; tolderías medianas de unos treinta habitantes, de cuatro a seis ranchos, a veces cercanas entre sí, y grupos menores de unas diez y quince personas. Considerando a la banda o grupo local como la unidad sociopolítica básica de estos indígenas (Citro, 2006) podemos vincularla, a partir del número de sus integrantes, a las tolderías medianas, en tanto los grupos menores que se señalan pudieron tratarse de familias que se desgajaban de un grupo local para la marcha. Diversas bandas aliadas, a su vez, podían acampar juntas en determinados momentos del año, conformando las tolderías mayores. Este mecanismo de agregación-dispersión, ha sido señalado para los mocovíes de los siglos XVIII y XIX (Nesis, 2005; Citro, 2006).

Las señales de modificación del paisaje halladas por los expedicionarios, algunas de larga data, evidencian que aunque el nomadismo de estos grupos, tanto como el mecanismo de agregación y dispersión pudieron haberse utilizado como tácticas defensivas ante las agresiones que estaban sufriendo, eran pautas de desplazamiento y ocupación del espacio que las precedían. La circulación de los diversos grupos indígenas se producía dentro de un mismo territorio, más o menos delimitado y reconocido por sus vecinos -como veremos-, e implicaba el retorno a los mismos lugares tras ciertos períodos. Por lo tanto, la presencia de tolderías deshabitadas no significaba el abandono definitivo de esos parajes, sino una movilidad y una rotación ligadas al aprovechamiento más eficiente de los recursos.

El tiempo de permanencia en un lugar podía variar, siendo menor en el caso de los simples campamentos de viaje y más prolongado en aquellos donde se advierte la energía invertida en la construcción de grandes ranchos; una semana,
1. AGPSF. AG, T. 42,1875 , fs. $1342-$ 1366.

2. AGPSF. AG, T. 42, 1875, f. $1691 \mathrm{v}$. 
3. AGPSF. AG, T. 42,1875, fs. 1354 y $1357 \mathrm{~V}$., respectivamente.

4. AGPSF. AG, T. 42,1875, f. $1357 \mathrm{v}$.

5. AGPSF. AG, T. 42,1875 , fs $1690 \mathrm{v}$, 1692 y $1338 \mathrm{v}$., respectivamente. quince o veinte días especificaba el misionero Constancio Ferrero a mediados del siglo XIX, lo que dependía, entre otras cosas, de las posibilidades para la caza (Beck Bernard, 1991). Los informes de los colonos se encargan de señalar la variedad de presas que se podía encontrar en la región: nutrias, carpinchos, aves acuáticas, gamos, osos hormigueros, tropillas de jabalíes; tanto como su abundancia en algunos parajes y su ausencia en otros. El aprovechamiento de esos recursos por parte de los indígenas se aprecia en la presencia de elementos ligados a su elaboración y consumo, como recipientes de cerámica y hornos para la cocción de carne y el almacenamiento de cuises, pieles de avestruz y cueros de gamos:

[...] de los cuales los indios é indias se fabrican una clase de traje que consiste en un bestido ó especie de enaguas atado á la cintura y que nó alcanza á cubrir las rodillas; lo demás del cuerpo esta descubierto.

[...] tenian una buena provista de ratones sin cola y parece este manjar ha seducido á nuestro comandante porque se ha comido unos. ${ }^{3}$

Junto a la caza se practicaba la recolección, la que se hacía en parte con un palo de quebracho para extraer raíces y parece haber sido tarea de las mujeres, -una de las cuales lo usará en una ocasión como arma contra los asaltantes. "En la cena bemos á los indios comer raizes que se esemejan algo á la mandioca; nos dicen que provienen de una especie de cactus enredadera del cual hemos visto cantidades en esos montes; es el alimento favorito de los javalies". ${ }^{4}$ Se consigna además el acopio de palmeras cortadas para consumir la médula y con cuyas hojas las mujeres hacían sombreros.

La ocupación de una toldería dependía también de la disponibilidad de agua y las más grandes, tanto como los conjuntos de tolderías medianas cercanas entre sí, se erigían junto a lagunas o pozos de agua artificiales que construían los indígenas para enfrentar los períodos de sequía.

El baqueano cautivo [...] nos rindió servicio especial llevándonos directamente hasta unos pozos hechos por los indios que el nos había dicho eran cerca de una toldería grande $[\ldots]$.

descubrimos unos pozos cerca de otra toldería que parceria de mas concideracion que la ultima [...].

Despues de haber dejado este ultimo punto no encontramos agua ninguna sino la que estaba en los pozos de los Indios; los cuales estaban en pequeño numero y muy alejados los unos de los otros. ${ }^{5}$

Estos pozos se encontraban estratégicamente distribuidos en el territorio recorrido frecuentemente por los grupos locales. Es decir, a lo largo de los caminos trazados por los mocovíes en todas direcciones y que los colonos aprovecharon para avanzar sobre las tolderías;

Tres buenos caminos salen de esta aldea y se dirijen hacia el Norte y el Oeste.

Nos ponemos en camino hacia el N.0. siguiendo un sendero hecho por los indios al costado del monte.

Esta región está cruzada en todas direcciones por sendas de los indios [...] seguimos las sendas de los indios y es el mejor medio de llegar hasta ellos. ${ }^{6}$ 
Pozos artificiales de larga data, hornos para la cocción de alimentos, caminos y senderos, tolderías de diversos tamaños, ranchos de estructuras variadas, vasijas de cerámica, herramientas de madera, productos de origen vegetal y animal almacenados forman parte del escueto inventario de elementos culturales que puede hallarse en los informes de las expediciones realizadas contra los indígenas. Constituyen una pequeña muestra de su cotidianeidad material y de su adaptación a las condiciones ambientales.

En los ataques y saqueos que los colonos realizan sobre las tolderías se encuentran además algunos bienes provenientes de la sociedad euro-criolla, como yerba, café molido, azúcar y objetos de hierro que: "Asegun la opinión de nuestro gefe Dn Guillermo Moore este proviene de la existencia de relaciones amigables con los Indios del Rey",; es decir, de los intercambios con los mocovíes reducidos entre quienes tenían parientes. En otros casos, como el de unos botones del ejército pertenecientes a un militar que habían matado, procedían de la lucha fronteriza.

Aunque la base de la subsistencia indígena se encontraba en la caza y la recolección, los informes de los colonos evidencian también cierta actividad pastoril. En algunas tolderías se indica la presencia de caballos, ovejas y vacas, en buenas condiciones en general. También se alude a lugares destinados al pastoreo, y técnicas para favorecerlo como la quemazón de sectores de vegetación para obtener pastos tiernos. Algunos de estos animales vacunos y equinos provenían de los ataques que los indígenas realizaban sobre la frontera.

En la historiografía hay una tendencia a explicar la larga guerra de frontera, que por espacio de tres siglos se desarrolló en el Chaco meridional, a partir de las razones formuladas por el colonizador -español, criollo o inmigrante. Aunque la amplia bibliografía sobre este tema, reseñada críticamente por Lucaioli (2005), exceda los objetivos de este trabajo, señalaremos que en diversas versiones se sostiene que los indígenas del Chaco, atraídos por los bienes -ganado centralmente- de la sociedad euro-criolla, realizaban sus ataques o malones sobre algunas poblaciones de la frontera para obtener un botín que luego intercambiaban en otras; motivando así la realización de expediciones punitivas o de castigo por parte de las fuerzas colonizadoras.

La presencia de un móvil económico, sin embargo, no alcanza a explicar algunas características de los ataques concretos realizados por los mocovíes sobre las fronteras, como los desafíos a duelos singulares a quienes salían a enfrentarlos (Paucke, 1942-1944). El castigo de las afrentas sufridas en una especie de reciprocidad negativa constituía, por otro lado, un mandato cultural para estos, presente incluso en sus mitos de origen como el del árbol "Nalliagdigua" registrado por Guevara (Guevara, 1882: 50). No sabemos si los mocovíes de mediados del siglo XIX conocían ese mito registrado por Guevara un siglo antes pero advertimos que otros, citados por este misionero, continuaban vigentes todavía en el siglo XX. Además, el franciscano Constancio Ferrero señalaba, en la época que estudiamos, que: "Cuando han recibido alguna injuria, o sufrido algún daño, son implacables en la venganza" (Beck Bernard, 1991: 82), y 100 años antes el cacique Ariacaiquin manifestaba que:

[...] los españoles han engañado demasiado a nuestros antepasados, su amabilidad era una traición y una amistad simulada. Pues solo trataron de hacernos esclavos y matarnos a azotes [...] desde ese tiempo nosotros no hemos podido aguantarlos y los hemos perseguido como a nuestros peores enemigos hereditarios (Magrassi, 1989: 96). 
En la explicación dada por los propios mocovíes sus ataques sobre la frontera, aunque pudieran proporcionarles a veces un botín económico, tenían una finalidad punitiva y de resistencia en primer lugar.

Más allá de las razones expresadas por unos y otros, advertimos que aun cuando está testimoniada la existencia de intercambios con las ciudades fronterizas, ni la regularidad ni el volumen de los mismos están establecidos claramente; mucho menos su peso en la economía mocoví, como tampoco el del botín. Por el contrario, algunas referencias testimoniales a la práctica de la caza y la recolección, aunque tampoco ofrecen datos cuantitativos, apuntalan la imagen de una economía crucialmente dependiente de esas actividades, incluso en el siglo XIX y entre los indígenas reducidos. En diciembre de 1858, Evaristo Ponce escribía al gobernador santafesino sobre la hambruna que estaban atravesando los mocovíes de San Pedro:

[...] no ha quedado un solo vicho del campo, ni sorrino, ni raton que no hallan comido y no les quedaba mas alimento que los huesos tirados de desecho que los reunian para hacerlos hervir y tomar aquella agua y sin embargo Exmo Sor estos indios no robaban $[\ldots] .^{8}$

Por último, la explicación de la guerra fronteriza a partir del modelo malones botineros y expediciones punitivas soslaya tanto el hecho de que las campañas militares realizadas contra los indígenas entre los siglos XVII y XIX aseguraron una permanente provisión de cautivos destinados a la servidumbre (Green y Molina, 2018), como al botín principal de la larga contienda: la tierra.

Los informes de las expediciones de la década de 1870 van registrando topónimos en español, pero evidentemente indígenas en su origen en tanto remiten al territorio que les pertenece, a sus conocimientos, a sus creencias y a sus historias. Se habla de la Laguna de la gran bestia, nombre dado al anta o tapir, que era raro en la zona y cuya carne era estimada por los mocovíes; del paraje llamado El cuero del tigre, producto codiciado y bien pagado por la sociedad criolla, lo que llevaba a algunos indígenas a cazarlo aunque con cierto remordimiento y muchos "no lo harían por nada" (Perkins, 1867: 61), ya que para ellos el tigre o jaguar participaba en algo de la naturaleza humana; y de la cañada del Pájaro Blanco o cigüeña, ave venerada al punto que algunos "Se afligieron mucho un día, cuando uno de los americanos mató una de ellas con su rifle" (Perkins, 1867: 51).

Algunos de esos topónimos, como "el parage en el cual nos hallábamos se llama el monte de las palmeras de los Tobas", ${ }^{9}$ refieren directamente a los derechos territoriales reconocidos entre los indígenas. Si bien la idea de propiedad privada de la tierra les era ajena debemos considerar la existencia de una especie de propiedad colectiva, en la medida en que claramente cada grupo étnico poseía derechos exclusivos sobre determinados espacios, reconocidos por los demás: "no hay palo-negro para lanzas, sino internándose muy adentro del territorio de los Tobas, al otro lado del Rey" escribe Perkins (1867: 44). Los límites que separaban los territorios de los tobas meridionales de los mocovies y espineros eran respetados por unos y otros. Había relaciones de intercambio entre los diversos grupos, como se observa en los informes de los colonos, pero no se entraba en territorio ajeno sin permiso. Así los expedicionarios que bordean el territorio de los tobas, mientras persiguen al cacique mocoví Juan Gregorio, pueden dar por sentado que este no se encontraría allí. Los javierinos que, por su parte, extendían sus expediciones de caza hacia el norte de la reducción, llegaban hasta Pájaro Blanco a dieciocho leguas de la misma 
y "De ahí para adelante no se atreven a pasar, pues dicen que ya es territorio perteneciente esclusivamente a los montaraces" (Perkins, 1867: 24). Ambos grupos "tienen una especie de convenio tácito, de que hasta este punto se entienden los campos donde les es permitido cazar a los paisanos reducidos" (Perkins, 1867: 49). Es decir, que la zona de Pájaro Blanco era el límite entre los territorios que podían explotar conjuntamente javierinos, mocovíes y espineros y los que pertenecían exclusivamente a los dos últimos grupos, que se extendían por el norte hasta el Rey -más allá del cual comenzaba el territorio de los tobas sureños.

El amplio espacio observado se encontraba por lo tanto, a mediados del siglo XIX, sujeto a un sistema de normas y derechos de propiedad que incluían a la propiedad territorial colectiva, y era respetado por los diferentes grupos, aun en ausencia del privilegio del uso exclusivo de la fuerza, y no necesariamente asentado sobre un consenso "tácito" como suponía Perkins.

Resulta difícil intentar una estimación numérica de las personas que lo habitaban en la época, aunque sabemos que los cazadores-recolectores requieren grandes extensiones de tierra para poblaciones reducidas (Bartolomé, 2003). Los informes de las expediciones de 1875 aportan algunos datos numéricos sobre personas avistadas, asesinadas y cautivadas, a partir de los cuales puede intentarse calcular el total de indígenas que fueron contactados -o que se supo con certeza que se hallaban cerca. Sin embargo, es posible que algunos grupos se mantuvieran aislados y sin identificar, por lo que solo podemos obtener el número mínimo de habitantes indígenas para la zona en ese año.

Considerando solo los grupos que fueron efectivamente contactados y aquellos de los que se tuvo certeza de su ubicación, registramos en el área tres tolderías grandes, con los caciques José Domingo Peralta, José Ignacio y Dionisio, que pudieron tener alrededor de 100 integrantes cada una. Más alejadas estaban las de Juan Gregorio y Roque que por ser caciques más influyentes tendrían más seguidores, tal vez 150 personas cada uno. Contabilizando también grupos menores de nueve -cacique Nedaré-, trece y veinticinco personas, que fueron atacados, y uno de 35 que se redujo en Concepción obtenemos la cifra de 682 personas. Después de cinco años de permanentes ataques de los colonos y del ejército, como veremos, había una población que rondaba las 700 personas como mínimo: mocovíes, espineros y javierinos, en la zona observada.

\section{Los colonizadores}

Durante la segunda mitad del siglo XIX, y en el marco de las crecientes posibilidades que se abrían a partir de la vinculación con el mercado mundial, el Estado en consolidación promoverá la inmigración europea para poblar el llamado desierto y asegurar el progreso, siendo la provincia de Santa Fe y los territorios del Chaco austral los elegidos para impulsar la colonización a partir de inmigrantes. Este proceso ha sido objeto de numerosos estudios; para el área que observamos la historiografía ha enfatizado su carácter de gesta heroica insistiendo en los obstáculos que enfrentaron los inmigrantes y en sus esfuerzos para superarlos (Sager, 2005; Tourn Pavillon, 2005, 2010; Minniti Morgan, 2012), por sobre las ventajas otorgadas por el Estado. También se han investigado las relaciones de los inmigrantes con el contexto social, el Estado, y los indígenas (Duarte, 1970; Maffucci Moore, 2005, 2007; Dosztal, 2013, 2016). Nos limitaremos, por lo tanto, a señalar algunos aspectos que nos permitan explicar el tipo de vínculo que se estableció con estos últimos. 
10. AGPSF. AMG, SGyC, T. 319, Exp. 800 .
El éxito de la primera etapa colonizadora iniciada con la colonia Esperanza en 1856, en las llanuras del centro-oeste santafesino, se expandirá en la década siguiente al norte de la frontera, siguiendo la costa del Paraná. Con el objetivo de explorar y mensurar esos territorios para su privatización Guillermo Perkins emprende una expedición hasta el Rey en 1866, de la que eleva un informe al gobernador Oroño (Perkins, 1867). Ese mismo año se establece la colonia California, al norte de la reducción de San Javier, y al año siguiente la colonia Galense (Andino, 1998). En 1867 también se delinea la colonia Francesa, al sur de San Javier (Maffucci Moore, 2005), y en 1869 la colonia Eloisa, al norte de la California (Dosztal, 2013). De ese año es el decreto de concesión de tierras para la colonia Ausonia, que se entregarían gratis a inmigrantes italianos. Abandonada ante un ataque toba en 1871, los colonos vuelven cuando la línea de frontera se traslada al Rey y conforman la colonia Vanguardia (Roselli, 1980). En 1870, se delinea la colonia Alejandra (Roselli, 1980; Maffucci Moore, 2005) y en 1873 la colonia Romang (Tourn Pavillon, 2010), llamada colonia Malabrigo en los primeros años (Sager, 2005). Más allá de sus diversos orígenes y de sus trayectorias individuales, los colonizadores constituyeron un colectivo con características e intereses comunes frente a los propietarios indígenas de la región.

Excepto la colonia Francesa, todas las poblaciones mencionadas se establecieron fuera de la línea de frontera como observan diversos autores (Roselli, 1980; Maffucci Moore, 2005; Tourn Pavillon, 2005, 2010; Dosztal, 2013, 2016); es decir, más allá del territorio controlado efectivamente por los estados nacional y provincial. Aunque la constitución santafesina de 1863 establecía que su territorio llegaba hasta el arroyo del Rey (Maffucci Moore, 2007), este no era un punto de vista compartido por los indígenas, que anclaban sus derechos de propiedad en otros principios preexistentes y reconocidos por los diversos grupos. Aun en 1894, en otro contexto, el cacique Mariano Salteño podía aludir en una nota a: "hombres ancianos que son testigos oculares de nuestros principios como pobladores y de nuestro despojo por absoluto despotismo" ${ }^{10}$

Pero no se trataba simplemente de dos visiones contrapuestas; los colonos no ignoraban que recibían tierras que ya se encontraban ocupadas y fuera del control estatal. Esto se evidencia en los bajos precios de los contratos de compra-venta (Dosztal, 2013), en su establecimiento inicial dentro de empalizadas (Tourn Pavillon, 2005, 2010; Dosztal, 2013) y en su arribo a la región portando sus armas de fuego. En febrero de 1871 fue publicado en Europa un informe de Ignacio Rickard, donde ponderaba el clima, la tierra y los recursos (Tourn Pavillon, 2005) y recomendaba a los inmigrantes que trajeran herramientas, vestimentas, y revólveres (Dosztal, 2013). Se informaba que los indígenas cercanos carecían de armas peligrosas y caballos y que el Ministro de Guerra se comprometía a trasladar la línea de frontera hacia el norte (Dosztal, 2013).

En la medida en que la colonización de la zona precedía al Estado, en términos efectivos, las tierras privatizadas no podían ser fiscales más allá del discurso. Su bajo precio y la llegada de los colonos con sus armas dejan al descubierto la verdadera naturaleza de la supuesta transacción; se trataba en realidad de expropiar a sus dueños indígenas y de suprimir sus derechos, apoyados en normas preexistentes, mediante la violencia. Las acciones de resistencia emprendidas por estos en defensa de sus tierras y recursos serán re-categorizadas a partir de una nueva normativa, impuesta externamente por las armas, como agresiones y delitos contra la propiedad de los colonos, invirtiendo en el discurso los términos de lo que en realidad se estaba produciendo. 
El primer problema a resolver para los colonos y el Estado fue el de las poblaciones reducidas de la costa. La creación de la colonia indígena de San Javier, en el contexto de avance del frente colonizador en 1866, respondió al intento de circunscribir a los mocovíes en un espacio reducido, ya que se deseaba ocupar el territorio por el que se desplazaban libremente. Dicho propósito solo se ajustaba provisoriamente a la lógica del proceso, en la medida en que la avidez de tierras del frente colonizador terminará incluyendo también a aquellas en las cuales se intentó circunscribir a los indígenas.

Esto quedó evidenciado desde el inicio, cuando los californianos solicitaron al gobierno un terreno que ya había sido otorgado a los javierinos: "Demasiado extenso ese terreno para lo que puede necesitar ni aun aumentada en mucho la colonia indígena que esta establecida en dicho pueblo" (Andino, 1998: 27). El propio Perkins, que había convencido a los javierinos sobre la necesidad de que se mantuvieran en su reducción en tierras que les otorgaría el gobierno y de "obedecer las leyes", apoyó la demanda de los colonos (Perkins, 1867: 63). Los mismos que con una mano ofrecían a los indígenas de San Javier su propia tierra se la quitaban con la otra.

El siguiente paso sería estigmatizarlos. Al poco tiempo comenzaron las quejas de los colonizadores, y en noviembre de 1871 se dirigían al presidente para reiterar que los indios reducidos de San Javier y Santa Rosa de Calchines eran "gentes ociosas que no se ocupan del trabajo sino del robo y pillaje" (Andino, 1998: 27) y demandar que "sean removidos lejos de las inmediaciones de nuestra colonias y puestos en un lugar lejano de donde no nos puedan estorbar". Pedían que no se introdujeran en las colonias "so pena de ser considerados como montaraces y exterminados como enemigos armados" (Andino, 1998: 27-28). Esta última expresión permite vislumbrar que, al igual que la circunscripción, el traslado de los indios a otros lugares solo se percibía como una salida provisoria. Si el proyecto era apoderarse de tierras que ya tenían dueños, el camino era claro para los colonos y lo planteaban sin ambages al presidente de la República;

Exmo. Señor, el sistema actual seguido entre los indios del Chaco llamados "mansos" no tiene otra tendencia que la de extinguir a los colonos y dejar abandonado por otro siglo más la civilización del desierto; por consiguiente hay que elegir entre dos cosas: la destrucción de las colonias del Chaco o el alejamiento o exterminio de los bárbaros (Andino, 1998: 28).

La lógica de acumulación que presidia el proceso de despojo territorial y privatización llevaría, tarde o temprano, a que el frente colonizador exigiera también aquellas tierras a las que los indígenas fueran alejados. La intención de aniquilarlos será planteada desde diversos lugares -empresarios de la colonización, colonos, funcionarios del Estado- sin eufemismos. Rickard escribía al Mayor Oroño en octubre de 1871 que: “En cuanto llego a Buenos Aires, tal vez arregle algo con el Presidente para limpiar el Chaco de estos picaros" (Tourn Pavillon, 2005: 3); Perkins sostenía: "el propósito de limpiar el territorio de Indios hasta El Rey" ,"es una palabra muy dura pero no hay nada que hacer con ellos" [... "parece no haber otra alternativa que su total destrucción" (en Maffucci Moore, 2007: 278-279). Ante el inminente avance de la frontera hasta el Rey, el coronel Obligado exponía sus propuestas "a fin de reducir o esterminar los indios Montaraces que hoy moran al interior de esa línea" (Roselli, 1980: 61), y en 1885 recomendaba con toda crudeza a un subordinado no perder "de vista el objetivo de sus operaciones que es el de concluir con los mocovíes" (Gallagher, 2007: 82). 
Como señalamos, el Estado va por detrás de los colonos en la zona. En diciembre de 1871, Obligado adelanta parcialmente la frontera poniendo en marcha su plan de llevarla hasta el Rey; sube por la costa del Paraná hasta ese punto, donde arriba en abril de 1872, y explora hacia el oeste hasta Santiago del Estero para tender la nueva línea de fortines (Roselli, 1980).

La amenaza que el avance del frente colonizador implicaba para su mundo fue tempranamente percibida por los mocovíes, tanto reducidos como montaraces "creen que esas colonias eventualmente arruinaran sus cotos de caza y tomarán posesión del Chaco", se advertía en la prensa en 1868 (Maffucci Moore, 2007: 298).

La tensión en la zona fronteriza creció a fines de la década de 1860 entre reducidos y colonos; en 1865 el empresario colonizador Teófilo Romang fundaba la colonia Helvecia al sur de San Javier, y se jactaba de lo duro que había resultado un cacique al que tuvo que administrarle dos dosis de veneno para terminar con su vida (Magrassi, 1989: 91). En enero de 1869, el cacique cayastacero Rufino Valdez elevaba sus quejas al gobierno por los abusos y asesinatos cometidos por los colonos. ${ }^{11}$ En toda la frontera, y a diferencia de Valdez, los mocovíes reaccionaron ante el avance con ataques sobre colonias, obrajes y fortines.

El 6 de abril de 1870 atacaron la colonia Galense (Maffucci Moore, 2007) y al mes siguiente la de Eloisa donde mataron a dos inmigrantes: "una mujer rogó por su vida, los indios le quitaron el pañuelo que llevaba en la cabeza y le gritaron que se fuera", según una nota de los colonos a la prensa (Maffucci Moore, 2005: 8) -orden que se ajustaba al móvil principal de sus acciones bélicas.

Algunos autores han realizado un inventario minucioso de estos ataques indígenas, seguido de vagas alusiones a las campañas de exterminio realizadas por los inmigrantes. En un esfuerzo por presentar a estas como reacción y castigo ante abusos cometidos por los indios han emprendido una especie de búsqueda de quién arrojó la primera piedra, que pierde relevancia en un contexto de invasión territorial como el que se estaba produciendo.

\section{Las campañas de exterminio}

Con el avance de las fuerzas militares hacia el norte y la construcción de una nueva línea de fortines, las colonias costeras mencionadas en el punto anterior quedaron dentro de la frontera estatal. El control sobre el territorio así ocupado, sin embargo, no era completo y a retaguardia y vanguardia de la nueva línea continuaban desplazándose grupos mocovíes. Tanto desde los estados nacional y provincial como desde las colonias de inmigrantes se implementaron acciones, a veces coordinadas, con una misma finalidad; despejar la zona de indígenas. En el transcurso de la década de 1870 se sucederán numerosas expediciones armadas, integradas por colonos de la costa, militares, o fuerzas conjuntas; en este último caso, bajo las órdenes de W. Moore, norteamericano que encabezaba a los inmigrantes. Por momentos parece haber existido, incluso, una especie de competencia en la tarea de aniquilar a los indígenas y los colonos aludían al celo de los oficiales criollos ante sus éxitos:

Dejamos la comandancia del Rey á nuestra izquierda porque se dice que los oficiales están algo celosos de que se haga lo que ellos manifiestan nó pueden hacer [...] el cuerpo de oficiales (Estado Mayor) esta muy contrariado de 
que los gringos se ocupen de la seguridad de las Colonias y demuestren con muy pocas fuerzas relativamente a aquellas de que disponen las fronteras que se puede llegar a hacer lo que ellos casi nunca consiguen es decir matar y prender indios. ${ }^{12}$

En algunos de los informes aparecen los listados de los perpetradores directos de las campañas privadas, en su mayoría colonos provenientes de Helvecia, California, Eloisa, Alejandra y Romang. Pero no se trataba de una suma de individualidades, quienes marchaban encarnaban un proyecto que involucraba a los colonos como sujeto colectivo y, por lo tanto, contaban con el apoyo y adhesión general en las colonias.

Las fuerzas estatales, por su parte, actuaban en sintonía con el interés privado de los colonos. Incluso en los casos en que estos marchaban solos contra los grupos indígenas, el gobierno provincial aportaba pertrechos, caballos y provisiones. El armamento, en cambio, era de los propios inmigrantes y estaba conformado por las armas de fuego más avanzadas de la época: "rifles á repetición de Winchester, algunos tenían de Wetterleys Sinders y algunos Remingtones", ${ }^{13}$ que contrastaban fuertemente con el armamento indígena mencionado en los mismos informes: lanzas, lazos y boleadoras.

En 1875 los colonos enviaron reportes al gobierno provincial de tres de las expediciones autorizadas en ese año, pero no todas las acciones realizadas -ni sus pormenores- eran informadas a aquel. En los libros parroquiales de San Javier se registra en enero de 1871 que los colonos realizaron una matanza de javierinos, hecho que se repitió un mes después a manos de colonos y soldados. Mientras las fuerzas militares que avanzaron hacia el Rey en 1872 se encontraron en el camino con colonos que regresaban de otra campaña (Roselli, 1980: 63).

La razón que se argumentaba para realizar esas expediciones siempre era el castigo de crímenes y robos que, en el marco de la nueva legalidad que se imponía mediante las armas, eran atribuidos a los indígenas, rotulados como: ladrones notorios; bandidos montarazos; bandidos que infestan esos parajes; salteadores. La historiografía regional ha reproducido, en general, las justificaciones esgrimidas por los colonos; los indios invadían para robar y cautivar, los colonos se defendían y realizaban expediciones en busca de justicia ante la ausencia del Estado (Maffucci Moore, 2007; Dosztal, 2016; Minniti Morgan, 2017). Este modelo se encuentra también en Duarte (1970) quien observa, al mismo tiempo, el ensañamiento y la falta de escrúpulos de los colonos, en tanto Vigo (1988) ha analizado sus expediciones como genocidas.

Algunas de estas, realizadas en 1875, tenían por objetivo explícito recuperar dos cautivos y castigar al cacique Juan Gregorio, instigador de ataques a las colonias. Sin embargo, ciertas expresiones anotadas por los mismos colonos, como la referencia a "operaciones futuras", ${ }^{14}$ o la insistencia en el valor de las tierras que van recorriendo para la agricultura, ${ }^{15}$ tanto como el accionar desplegado por estos, advierten sobre la presencia de otras motivaciones no explicitadas. Poniendo expresiones y acciones en contexto es evidente que el fin de las expediciones no era el castigo de hechos puntuales, sino despejar las tierras invadidas de sus dueños indígenas mediante una suerte de limpieza étnica.

En el diario de la expedición de septiembre de 1875 se indica que: "como los Tobas nunca cometieron saqueos en nuestras Colonias creemos que nó es
12. AGPSF. AG, T. 42,1875 , fs. $1362-$ 1363.

13. AGPSF. AG, T. 42, 1875, f. 1338.

14. AGPSF. AG, T. 42, 1875, f. 1693. 15. AGPSF. AG, T. 42, 1875, f. 1344. 
16. AGPSF. AG, T. 42,1875 , f. 1355 .

17. AGPSF. AG, T. 42, 1875, f. $1356 \mathrm{v}$.

18. Libro nuevo de entierros de la Reducción de Calchines 1856-1889. Iglesia de San Javier, fs. 92-93. deber nuestro ir á perturbarlos" ${ }^{16}$ Sin embargo era la lejanía de estos, en ese momento, del territorio que se buscaba despejar y consolidar, la que los ponía a salvo. En realidad se trataba de preservar las fuerzas y los medios disponibles -caballos y municiones- para objetivos más inmediatos. Mucho más cerca se encontraba el cacique Juan Gregorio, supuesto objetivo de la expedición, a quien los inmigrantes reconocían como el instigador de los ataques a las colonias y poseedor de los dos niños cautivados entonces;

Creemos también que los niños robados en la Colonia Romang el 29 de junio ultimo deben estar con él. [Sin embargo] La falta de agua y el estado de nuestros caballos nos impiden ir á saludarle, pero esta nó es sino una apuesta postergada, mas tarde esperamos hacerles pagar sus cuentas atrazadas [...]. ${ }^{17}$

Que el objetivo de los colonos no era castigar a supuestos criminales se comprueba claramente en la masacre de javierinos realizada en enero de 1871, no comunicada al gobierno y registrada en los libros parroquiales de la iglesia de San Javier por Fr. Ermete Constanzi, el 12 de ese mes:

Hallándose ausentes de este punto varias familias indígenas como costumbre de cazar y pescar sobre las costas de este Rio San Javier, fueron sorprendidas por los Colonos norte Americanos encabezados por Dn Guillermo Moore y después atados á los hombres, los condujeron á la misma costa del Rio adonde por los sureferidos Colonos fueron muertos 11 indios qe son Antonio Valdez con su legma mujer Timotea Assake y tres hijos, Francisca de seis años, Eusebio de tres años y Romualdo de once meses, Francisco Seco, su legma mujer baleada qe aun vive, una hija de dos años y medio, Serafina Nitigui y un hijo de diez meses qe se llamaba Isidoro. Rosa Tiené y un hijo de pecho. ${ }^{18}$

El cura consigna, además, que el coronel Obligado había facultado a los colonos para considerar montaraz a todo indio que se hallara fuera de su reducción. Es evidente que la colonia indígena de San Javier había sido pensada como cárcel a cielo abierto.

Días antes de la matanza los indios habían lanceado a un saboyano en la colonia Francesa. Pero no fue esta un castigo a los autores ya que los mocovíes asesinados eran niños. Los colonos atacaron a dos familias de indígenas reducidos que recorrían su propio territorio explotando sus recursos como era su costumbre, y que no ofrecieron resistencia puesto que sobre once víctimas había dos hombres -que fueron atados- tres mujeres y seis niños -tres de los cuales aún no caminaban. La acción solo se comprende y explica a partir de la intención explícita, según vimos, de exterminar a los indígenas a los que se despojaba de sus tierras. Estas personas fueron asesinadas solo por pertenecer al grupo étnico que se buscaba destruir. Es así que los niños pudieron, de manera recurrente, convertirse en víctimas. Priamo (2000) ha recuperado la narración de una experiencia personal, hecha por un colono y referida a su juventud en la recién colonizada Malabrigo. En torno a 1890, cuando una partida de colonos bien armados asaltó un campamento indígena aduciendo que poco antes habían robado sus bueyes él y "los más encarnizados" entraron a rematar a los heridos una vez finalizados los disparos;

dio vuelta a una india tirada bocabajo, para asegurarse de que estaba muerta, y escondido, cubierto por ella, apareció un bebé desnudo, callado, con los ojos abiertos, prendido al pecho de la madre como si fuera un caracol (la imagen fue de don José). [...] alzó el winchester y le aplasto la cabeza de un culatazo (Priamo, 2000: 89). 
El suceso advierte sobre la prolongación de las expediciones realizadas por colonos armados, al menos hasta esa fecha y en el límite occidental de la zona que analizamos. Como hemos aludido, no todas se informaban detalladamente al gobierno provincial. La relatada, a su vez, era la forma en que generalmente se llevaban a cabo los ataques sobre las tolderías indígenas; el acercamiento sigiloso y el disparo a mansalva de las armas de fuego realizado sorpresivamente, preferentemente de madrugada, sobre los ranchos:

\footnotetext{
Al esclarecer avanzamos con toda precaucion hasta sentir la vecindad de una toldería grande; seguimos con silencio y orden la avanzada hasta aprojimarnos a la toldería cuando di la palabra de "Cargas". La sorpresa era completa, disparando los indios en todas derecciones. ${ }^{19}$
}

La técnica empleada, además de producir gran conmoción, huidas y muertes, evidentemente no facilitaba, aun cuando hubiese buenos tiradores entre los colonos, la discriminación de los objetivos; lo que se correspondía con la intención de aniquilar a los indígenas como grupo, sin distinciones de sexo y edad. Cuando los disparos cesaban podía iniciarse, con esa finalidad, la persecución de los sobrevivientes: “Nuestros compañeros que habian salido á las doce en dos grupos para inspeccionar mejor el monte vuelven hacia las cuatro despues de haber ultimado una de las mujeres heridas por la mañana". ${ }^{20} \mathrm{De}$ algunas expresiones volcadas en los informes elevados por los colonos sobre su accionar parece desprenderse cierta jactancia respecto de este, además de la saña manifestada frente a quienes más resistencia ofrecían.

\begin{abstract}
alcanzamos á la tolderia sin ser descubiertos; una mujer salio muy de prisa de su rancho e inmediatamente se puso a gritar -no abrió mas la boca de nuevo en este mundo $[\ldots]$
\end{abstract}

La tenacidad de la vida de ellos -es una cosa extraña uno de ellos que habiamos herido a la ida habia recorrido 55 leguas; lo encontramos á cerca de 10 leguas de la Tolderia volviendo. Recibió 3 balas antes de caerse de caballo y todavía alcanzo á uno de nosotros con sus boleador, no se murió hasta el 4 tiro [...]

La mujer parecia mas mala; fue preciso hacer uso de la fuerza para arrancarle un grueso garrote de quebracho achatado en una de sus extremidades del cual hacia uso para extraer raices de cactus. ${ }^{21}$

Los indígenas que no resultaban asesinados por las descargas sorpresivas intentaban huir y dar aviso a otras tolderías mediante quemazones, o volver a enfrentar a los asaltantes, solos o en compañía de sus vecinos. Algunos se entregaban sin ofrecer resistencia, tratando de poner a salvo a sus familias: "El hombre que tomamos prisionero no ha hecho ninguna resistencia cuando conoció que era imposible huir; se acurrucó contra un matorral con su mujer y sus dos hijos sin proferir una sola amenaza". ${ }^{22}$ Estos pasaban a formar parte de los grupos de cautivos con que generalmente retornaban esas expediciones y al llegar a la ciudad de Santa Fe eran dispersados y repartidos entre las familias acomodadas para su servidumbre (Green y Molina, 2018).

Aunque no se tomaban registros del número de los indígenas que morían después a causa de las heridas, ni de los que morían de hambre por el saqueo de sus animales, o de sed o de frío durante la huida (Bartolomé, 2003), podemos intentar -con cierta precisión- contar las personas asesinadas y cautivadas por las expediciones privadas que fueron documentadas. Así registramos a los once javierinos masacrados en enero de 1871, seis más y otros cuyos cadáveres no
19. AGPSF. AG, T. 42, 1875, f. 1690 .

20. AGPSF. AG, T. 42, 1875, f. 1356.

21. AGPSF. AG, T. 42, 1875 , fs. 1339 ; 1339v. y 1355 V., respectivamente.

22. AGPSF. AG, T. 42, 1875, f. 1355 V. 
fueron hallados al mes siguiente; veinte mocovíes asesinados y tres cautivados por la expedición de julio de 1875; cinco y diecinueve respectivamente por la de septiembre de 1875; 32 y 61 en noviembre del mismo año. En diciembre de 1876 fue asesinado el cacique Mateo, junto a cuatro de los suyos, por una expedición comandada por W. T. Moore; y poco después los colonos mataron a otros treinta que los atacaron (Maffucci Moore, 2007). Sabemos que hubo más campañas, como las mencionadas de 1872 y 1890, que no fueron reportadas. Por otro lado, en 1877 y 1878 se desarrollaron nuevas expediciones lideradas por Benjamin Logan Moore (Maffucci Moore, 2007).

Sobre una población que hemos estimado como mínimo en 700 personas para mediados de la década de 1870, observamos al menos 109 asesinadas y casi un centenar de cautivos en solo seis de las campañas efectuadas; prácticamente un tercio de la misma. Si se elevara a 1.000 el número de indígenas del área analizada tendríamos un $20 \%$ de muertes violentas y cautiverio sin distinción de sexo y edad, en un período de cinco años. A pesar del impacto que las expediciones analizadas tuvieron sobre los mocovíes de la zona estos lograron sobrevivir en las reducciones, o desplazándose hacia el norte.

Algunas voces de la época cuestionaron el accionar de los colonos desde la prensa (Maffucci Moore, 2007) y estos respondieron en diversas oportunidades a las críticas. Sostuvieron que los indios:

\begin{abstract}
fueron los primeros en atacar a las colonias sin haber sido provocados [...] bajo ningún punto de vista consideramos que hayamos sido inmisericordiosos. No aceptamos que se nos trate de crueles y sanguinarios, no estamos dispuestos a sufrir ultrajes [...] y si no podemos defendernos sin dudas preferiríamos abandonar el país [...]. No podemos admitir que se diga que los Indios han sido tratados sin piedad, aunque si hayan sido severamente castigados (Maffucci Moore, 2007: 293).
\end{abstract}

La existencia de cuestionamientos de parte de algunos contemporáneos llevó a los colonos a elaborar respuestas que no solo negaban sus prácticas, sino que contradecían lo expresado en sus propios informes reservados al gobierno. Además, bien pudieron haberlos llevado a ocultar, incluso en estos, ciertas acciones -como ocurrió con la masacre de mujeres y niños javierinos realizada en enero de 1871.

\title{
Algunas consideraciones finales
}

La ejecución por parte de colonos inmigrantes de expediciones privadas contra los grupos mocovíes que dominaban la zona nordeste de la actual provincia de Santa Fe, bien documentadas para la década de 1870 pero extendidas al menos hasta 1890, presentó un nivel de violencia y ensañamiento que resultó cuestionable para algunos contemporáneos. Esto provocó la elaboración, por parte de los colonos, de un discurso justificativo de su accionar y posiblemente influyó en el hecho de que no todas fueran informadas detalladamente.

Aludir casi en términos fatalistas a una supuesta crueldad humana, señalar que la desplegada por los colonos durante estas expediciones no fue, efectivamente, una excepción en la historia de América, considerar el conflicto entre inmigrantes e indígenas como una lucha inevitable en la que debía triunfar el más fuerte no explican este proceso concreto signado por una violencia 
organizada, sistemática y continua contra los mocovíes, con objetivos que incluían a los niños.

Los colonos de la costa se instalaron en tierras que estaban fuera del dominio efectivo del Estado, que se asumía como otorgante, y pertenecían a esos indígenas. En la segunda mitad del siglo XIX estos constituían una sociedad fundamentalmente cazadora-recolectora arraigada y adaptada a ese espacio enmarcado en normas consuetudinarias, que definían derechos territoriales y de acceso a los recursos y regulaban las relaciones entre parcialidades y grupos étnicos. Hemos discutido particularmente la afirmación de que su vínculo negativo con los colonizadores tuviera como base el interés de proveerse de bienes de manera violenta, poniendo el acento en la práctica de la venganza como uno de sus valores culturales y en la resistencia ante la invasión de sus tierras.

Las acciones de resistencia indígena fueron rotuladas por los colonos como robos que debían ser castigados, y desde la historiografía se concibió como intentos de hacer justicia por mano propia, ante la ausencia del Estado, a las expediciones realizadas por quienes en realidad estaban invadiendo ese territorio. El bajo precio de las tierras y su arribo a la zona con armas de fuego indican que la ausencia del aparato estatal, era en realidad una premisa para los inmigrantes.

Por su parte, es el propio discurso de los perpetradores de las masacres el que junto a sus acciones desvirtúa la afirmación de que buscaban castigar delitos. La violencia desplegada contra individuos que de ninguna manera podían cometerlos, ni ofrecer resistencia, evidencia la intencionalidad de exterminar al grupo étnico que se estaba despojando. A esto respondían las técnicas empleadas para atacar las tolderías y el asesinato de niños, tanto como los numerosos cautiverios de personas que luego eran dispersadas y repartidas lejos de sus hogares destruidos. 


\section{Fuentes documentales}

"Archivo General de la Provincia de Santa Fe (AGPSF).

Archivo de Gobierno (AG)

AGPSF. AG, T. 17, 1858.

AGPSF. AG., T. 34, 1869.

AGPSF. AG, T. 42, 1875 .

»Archivo del Ministerio de Gobierno (AMG), Sección Gobierno y Culto (SGyC), T. 319.

Iglesia de San Javier. Libro nuevo de entierros de la Reducción de Calchines 1856-1889. 


\section{Q Bibliografía}

Andino, M. D. (1998). El último malón de los indios mocovíes. Santa Fe, Centro de publicaciones Universidad Nacional del Litoral, Ediciones de la cortada.

"Bartolomé M. A. (2003). Los pobladores del "Desierto" genocidio, etnocidio y etnogénesis en la Argentina. Cuadernos de Antropología Social 17: 162-189. Disponible en Internet: https://doi.org/10.34096/cas.117.4604. Consultada el: 25 de febrero de 2019.

» Battcock, C., Gotta, C. y A. Manavella (2004). Frontera y poder: milicias y misiones en la jurisdicción de Santa Fe de la Vera Cruz, 1700-178o. Algunas reflexiones. Cuicuilco 11 (30). Disponible en Internet: https://www.redalyc.org/pdf/351/35103005.pdf. Consultada el: 17 de septiembre 2020 .

» Beck Bernard, L. (1991). Cinco años en la Confederación Argentina. 1857-1862. Santa Fe, Imprenta Legislativa de la Provincia de Santa Fe.

»Citro, S. (2006). Historia cultural en AA. VV.; Lengua, cultura e historia mocoví en Santa Fe: 21-102. Buenos. Aires, Instituto de Lingüística, Facultad de Filosofía y Letras, UBA. (Documentación y análisis de B. Guadaleri y S. Citro).

" Dosztal, I. (2013). El norte santafesino, una frontera de colonización entre la barbarie y la civilización, 1860-1880. Cuadernos de Antropología 9: 227-250.

»Dosztal, I. (2016). Alexandra Colony: Resiliencia en el norte de la Provincia de Santa Fe (1866-1904), Argentina. Estudios Fronterizos, nueva época 17 (34): 117-136. Disponible en Internet: http://dx.doi.org/10.21670/ref.2016.34.ao7. Consultada el: 16 septiembre 2020.

»Duarte, M. A. (1970). A la Conquista del Chaco Austral. Las Colonias Santafesinas de la Costa. Trabajos y comunicaciones 20: 147-168.

" Gallagher, E. (2007). “De puño y letra” Decodificación paleográfica. Cartas y documentos de General Manuel Obligado desde 1876 a 1881. Reconquista, Museo Municipal de Arqueología y Paleontología "Prof. Dante Ruggeroni”.

" Green, A. G. (2005). Los indios guaycurúes. Un aporte para su estudio. Ponencia presentada en el Congreso Argentino de Inmigración y IV Congreso de Historia de los Pueblos de la Provincia de Santa Fe. Amigos del Archivo General de la Provincia de Santa Fe. Esperanza, 10 al 12 de noviembre.

》 Green, A. G. (2018). Sauceros, criollos y colonos en las llanuras santafesinas a mediados del siglo XIX. Revista Binacional Brasil Argentina 7 (1): 97-120.

» Green, A. G. y G. Molina (2018). Cautivos indígenas en la sociedad santafesina del siglo XIX. Revista de la Junta Provincial de Estudios Históricos de Santa Fe LXXII: 125-154.

»Guevara, J. (1882). Historia de la conquista del Paraguay, Rio de la Plata y Tucumán I. Buenos Aires, Editorial F. Ostwald. (Introducción de Andrés Lamas).

» Lenton, D. y M. Nagy (2019). Presentación del Dossier: A 70 años de la Convención para la Prevención y la Sanción del delito de Genocidio (CONUG): actualización del debate en torno al genocidio de los pueblos indígenas. Memoria Americana. Cuadernos de Etnohistoria 27 (2): 6-9.

"Lenton, D.; Delrio, W.; Pérez, P.; Papazian, A.; Nagy, M. y M. Musante (2015). Huellas de un genocidio silenciado: los indígenas en argentina. Conceptos 493 (90): 119-142. Disponible en Internet: http://hdl.handle.net/11336/52773. Consultada el: 25 septiembre 2019 
" Lucaioli, C. (2005). Los grupos abipones hacia mediados del siglo XVIII. Buenos Aires, Sociedad Argentina de Antropología. (Colección Tesis de Licenciatura).

»Lucaioli, C. (2010). "Los espacios de frontera en el Chaco desde la conquista hasta mediados del siglo XVIII" en Lucaioli, C. y L. Nacuzzi (comps.); Fronteras. Espacios de interacción en las tierras bajas del sur de América: 21- 68. Buenos Aires, Sociedad Argentina de Antropología. (1a edición).

» Nacuzzi, L. (2010). Introducción en Lucaioli, C. y L. Nacuzzi (comps.); Fronteras. Espacios de interacción en las tierras bajas del sur de América: 7-19. Buenos Aires, Sociedad Argentina de Antropología. (1a edición).

" Maffucci Moore, J. L. (2005). Justicia, reclamos y representación en el nordeste santafecino (1870-1890). Ponencia presentada en el Congreso Argentino de Inmigración. IV Congreso de Historia de los Pueblos de la Provincia de Santa Fe. Asociación Amigos del Archivo General de la Provincia de Santa Fe. Esperanza, 10 al 12 de noviembre.

» Maffucci Moore, J. L. (2007). Indios, inmigrantes y criollos en el nordeste santafesino (1860-1890). Un caso de violencia en una sociedad de frontera. Andes 18: 275-302.

» Magrassi, G. (1989). Los aborígenes de la Argentina. Buenos Aires, Ediciones Búsquedayuchán.

» Martirén, J. L. (2014). Contrastes de frontera. Farmers y criollos en los prolegómenos de la gran expansión agraria de la Provincia de Santa Fe (1856-1875). Prohistoria 22: 81-105.

» Minniti Morgan, E. R. (2012). Colonia California y Galencia en el Pájaro Blanco. Córdoba, Ediciones Eta Carinae.

» Minniti Morgan, E. R. (2017). Fortín de san Javier. Córdoba, Ediciones Eta Carinae.

» Nesis, F. (2005). Los grupos mocovíes en el S. XVIII. Buenos Aires, Sociedad Argentina de Antropología.

"Paucke, F. (1942-1944). Hacia allá y para acá. Una estada entre los indios mocobíes (17491767). Tucumán, Universidad Nacionel de Tucumán.

»Perkins, G. (1867). Relación de la Expedición a El Rey en el Chaco. Rosario, Imprenta de El Ferrocarril.

»Priamo, L. (2000). "La foto recobrada” en Tedeschi, S. y L. Priamo; Vistas de la Provincia de Santa Fe. 1888-1892. Fotografías de Ernesto H. Schlie: 88-89. Santa Fe, El Litoral.

" Rosan, V. A. (2016). Mocovíes del chaco santafesino Una aproximación a sus prácticas Políticas. Tesis de doctorado. Facultad de Filosofía y Letras, Universidad de Buenos Aires. Disponible en Internet: http://repositorio.filo.uba.ar/handle/filodigital/5994. Consultada el: 3 de junio de 2020.

" Roselli, M. H. (1980). Historia de Reconquista. Primera Parte. Reconquista, Dirección General Municipal de Cultura. (Primera edición).

» Roulet, F. y M. Garrido (2011). El genocidio en la historia: ¿Un anacronismo? Corpus Archivos virtuales de la alteridad americana 1 (2). Disponible en Internet: http:// corpusarchivos.revues.org/1159. Consultada el: 2 de octubre de 2016.

» Sager, D. (2005). Romang, colonia de suizos. Ponencia presentada en el Congreso argentino de inmigración. IV congreso de historia de los pueblos de la provincia de Santa Fe. Asociación Amigos del Archivo General de la Provincia de Santa Fe. Esperanza, 10 al 12 de noviembre.

»Spota, J. (2010). Política de fronteras y estrategia militar en el Chaco argentino (18701938). En Lucaioli, C. y Nacuzzi, L. (comps.); Fronteras. Espacios de interacción en las tierras bajas del sur de América: 101-15o. Buenos Aires, Sociedad Argentina de Antropología. (1a edición) 
» Tamagno, Liliana (2011). Pueblos indígenas. Racismo, genocidio y represión. Corpus. Archivos virtuales de la alteridad americana, 1 (2). Disponible en Internet: http://ppct. caicyt.gov.ar/index.php/corpus/article/view/393. Consultada el: 25 de febrero de 2020.

» Tourn Pavillon, G. A. (2005). Pioneros británicos en el norte santafesino. Ponencia presentada en el Congreso argentino de inmigración y IV congreso de historia de los pueblos de la provincia de Santa Fe. Asociación Amigos del Archivo General de la Provincia de Santa Fe. Esperanza, 10 al 12 de noviembre.

» Tourn Pavillon, G. A. (2010). Historias de pioneros. En el Pájaro Blanco del norte santafesino. Alejandra, Santa Fe.

» Vigo, J. M. (1988). "Recuerdos de la costa. Un genocidio de indios en 1875". El Litoral, Santa Fe, 13 de mayo de 1988. 